\title{
PENURUNAN FUNGSI SISTEM PENGHIDU PADA PASIEN PENYAKIT PARKINSON: EPIDEMIOLOGI DAN TATALAKSANANYA
}

\author{
Andi Agung Riatmojo \\ Fakultas Kedokteran, Universitas Mataram, Indonesia. \\ Email: andiagungriatmojo.123@gmail.com
}

\begin{abstract}
Abstrak
Penyakit Parkinson secara umum merupakan suatu gangguan sistem saraf pusat yang sebagian besar manifestasinya merupakan gangguan fungsi motorik. Tetapi, gejala non motorik dewasa ini ditemukan sebagai manifestasi awal penyakit parkinson. Mengetahui bagaimana hubungan penyakit parkinson dan gejala non motorik yaitu kehilangan fungsi penghidu. Penulisan artikel ini mencakup berbagai sumber yang berasal dari jurnal ilmiah pada portal online publikasi jurnal seperti MedScape, Google Scholar, PubMed, dan NCBI, dengan kata kunci "gangguan penghidu dan penyakit parkinson" Gejala kehilangan fungsi penghidu dapat menjadi gejala pertama dari kelainan patologi pada central nervous system (CNS). Beberapa studi terkait penyakit Parkinson menyatakan hampir semua pasien yang di teliti didapatkan atrofi pada bulbus olfaktori sehingga menyebabkan pasien mengalami kehilangan fungsi penghidu (Anosmia). Pengaruh penurunan volume dari bulbus olfaktori dan pengaruh neurotransmitter juga dipercaya memengaruhi gangguan fungsi penghidu pada pasien penyakit parkinson. Anosmia merupakan gejala non-motorik yang paling sering dijumpai pada penyakit Parkinson, dan sering mendahului gejala motorik pada penyakit Parkinson. Pelatihan penciuman adalah modalitas yang menjanjikan untuk pengobatan disfungsi penciuman dan anosmia. Hasil tinjauan sistematis dan metaanalisis ini menunjukkan bahwa ini mungkin pengobatan yang efektif untuk disfungsi penciuman karena berbagai etiologi.
\end{abstract}

Kata kunci: Penyakit Parkinson, disfungsi penciuman, anosmia, kehilangan penciuman

\section{Abstract}

Parkinson's disease in general is a disorder of the central nervous system which most of its manifestations are motor function disorders. However, today's nonmotor symptoms are found as early manifestations of Parkinson's disease. To determine the relationship between Parkinson's disease and non-motor symptoms, namely loss of smell or anosmia. The writing of this article includes various sources originating from scientific journals on online portals of journal publications such as MedScape, Google Scholar, PubMed, and NCBI, with the keywords "olfactory disorders and Parkinson's disease". Loss of smell can be the first symptom of pathological abnormalities in the central nervous system (CNS). Several studies related to Parkinson's disease stated that almost all patients studied had atrophy of the olfactory bulb, causing the patient to experience loss of smell function (anosmia). The effect of decreasing the volume of the olfactory 
bulb and the effect of neurotransmitters are also believed to affect the olfactory dysfunction in patients with Parkinson's disease. Anosmia is the most common non-motor symptom in Parkinson's disease, and often precedes motor symptoms in Parkinson's disease. Olfactory training is a promising modality for the treatment of olfactory dysfunction and anosmia. The results of this systematic review and meta-analysis suggest that it may be an effective treatment for olfactory dysfunction due to various etiologies.

Keywords: Parkinson Disease, Olfactory Disfunction, Anosmia, Olfactory loss

Diterima: 23-12-2021

Direvisi: 12-01-2022

Diterbitkan: 20-01-2022

\section{Pendahuluan}

Penyakit Parkinson (Parkinson Disease) secara umum merupakan suatu gangguan sistem saraf pusat yang sebagian besar manifestasinya merupakan gangguan fungsi motorik. Tetapi, terdapat pula manifestasi nonmotorik yang dominan dijumpai sebagai manifestasi penyakit ini yaitu gangguan pada sistem penghidu atau hilangnya fungsi penghidu (Anosmia) (Tarakad and Jankovic, 2017). Anosmia, hilangnya indra penciuman, merupakan karakteristik nonmotorik yg diketahui sering mendahului timbulnya tanda-tanda motorik atau menjadi gejala awal pada penderita penyakit Parkinson (Fullard, Morley and Duda, 2017).

Gejala gangguan motorik pada penderita penyakit parkinson didominasi oleh bradykinesia, kekakuan, tremor istirahat dan ketidakstabilan postural. Disfungsi penciuman adalah manifestasi non motorik yang paling sering terlihat setelah kekakuan, dan bradykinesia (Wang, You and Liu, 2011; Altinayar et al., 2014). Anosmia terlihat pada hampir $90 \%$ pasien penyakit parkinson pada tahap awal penyakit mereka. Anosmia bahkan mungkin muncul bertahun-tahun sebelum timbulnya gejala motorik Studi neuropatologis juga menunjukkan bahwa sistem penciuman terlibat dalam tahap awal penyakit (Fullard, Morley and Duda, 2017; Rashed et al., 2020).

Penyakit parkinson umumnya terjadi pada rentang usia 65-70 tahun, onset terjadinya penyakit Parkinson dibawah 40 tahun sangat sedikit yaitu sekitar 5\% dari populasi berdasarkan penelitian kohort. Onset muncul lebih dulu pada orang yang memiliki riwayat penyakit keturunan penyakit Parkinson pula. Penyakit ini lebih sering dijumpai pada laki-laki dibandingkan dengan perempuan. Secara umum angka prevalensinya sebesar 100-200 orang per 100.000 populasi (Storstein, 2017).

\section{Metode}

Penulisan artikel ini mencakup berbagai sumber yang berasal dari bebagai jurnal ilmiah pada portal online publikasi jurnal seperti MedScape, Google Scholar, PubMed, dan NCBI dengan kata kunci yang digunakan adalah "Parkinson Disease, Olfactory Disfunction, Anosmia, Olfactory loss". 


\section{Hasil dan Pembahasan \\ Definisi}

Penyakit Parkinson (PD) adalah penyakit neurodegeneratif progresif yang ditandai oleh manifestasi motorik dan nonmotorik (DeMaagd and Philip, 2015). Gejala motorik PD terkait dengan hilangnya neuron dopaminergik striatal, meskipun adanya gejala non motorik mendukung hilangnya saraf di daerah non dopaminergik. Perubahan patofisiologis yang terkait dengan PD dapat dimulai sebelum timbulnya manifestasi motorik dan termasuk sejumlah manifestasi nonmotor, seperti gangguan tidur, depresi, kehilangan fungsi penghidu dan perubahan kognitif (DeMaagd and Philip, 2015). Pada PD, ada latensi yang panjang antara kerusakan pertama pada sel-sel di nukleus sistem saraf dan timbulnya gejala klinis. Gejala dan tanda PD biasanya tidak berkembang sampai 70-80\% neuron dopaminergik telah rusak. Dengan demikian, mengidentifikasi pasien dalam periode antara dugaan timbulnya hilangnya sel dopaminergik dan munculnya parkinsonisme klinis mungkin sangat penting untuk pengembangan strategi pengobatan neuroprotektif yang efektif (Emamzadeh and Surguchov, 2018).

Pemeriksaan sampel otak dari ratusan pasien PD menunjukkan bahwa proses patologisnya relatif seragam. Patologi pada tahap pertama dimulai di medula oblongata bawah, khususnya nukleus motorik dorsal saraf vagal, dan struktur penciuman anterior (Emamzadeh and Surguchov, 2018). Keadaan tersebut dapat menyebabkan munculnya anosmia atau disfungsi penghidu yang lainnya pada tahap awal penyakit parkinson (Altinayar et al., 2014; Tarakad and Jankovic, 2017). Pada tahap 2, lesi di nukleus motorik dorsal memburuk, inklusi berkembang di nukleus raphe bawah, dan neurit Lewy dapat diamati di lokus seruleus. Pada tahap ketiga substansia nigra terpengaruh. Pada tahap empat, lesi muncul di korteks, khususnya di mesokorteks temporal. Pada tahap lima, patologi muncul di bidang neokorteks temporal yang bersebelahan, sedangkan pada tahap enam keterlibatan kortikal terlihat jelas. Status kognitif pasien berkorelasi dengan tahap neuropatologis, yang mana status kognitifnnya bertambah buruk sesuai dengan tahapan patologis (Emamzadeh and Surguchov, 2018).

\section{Epidemiologi}

Prevalensi keseluruhan PD tampaknya lebih rendah dalam studi daerah benua timur dibandingkan dengan studi daerah benua barat. Hal ini dapat disebabkan oleh kombinasi faktor genetik dan lingkungan. Dalam sebuah meta-analisis dari 19 studi Asia dari tahun 1965 hingga 2008, tingkat prevalensi (standar usia untuk 2000 populasi WHO) adalah 51,3. 176,9 /100.000 dalam survei dari pintu ke pintu, tidak termasuk penelitian yang lebih tua dengan prevalensi rendah 16,7/10.000. Studi literatur menunjukkan tingkat prevalensi yang lebih rendah (35,8-68,3/100.000). 4 Sebuah meta-analisis terbaru dari 15 studi Asia di Cina (10 Cina, dua Hong Kong, tiga Taiwan) menunjukkan tingkat prevalensi 16-440.3/ 100.000 (usia standar untuk 2000 populasi WHO) (Abbas et al., 2018).

Dalam meta-analisis dari 39 studi Eropa hingga 2004, penulis melaporkan tingkat prevalensi 108-257/100.000 ketika mempertimbangkan hanya studi berkualitas tinggi yang menggunakan kriteria diagnostik standar, inklusi seluruh kelompok usia, dan 
skrining oleh ahli saraf berpengalaman.7 Meta-analisis lain dari delapan studi dari Inggris mengamati prevalensi 105-178/100.000. Pada kebanyakan studi dilaporkan kasus PD lebih banyak ditemukan pada 1.5 kali lebih tinggi pada pasien laki-laki. Ras dan faktor geografi juga dapat menyebabkan perbedaan insidensi PD. Ras Afrika serta pasien yang bertempat tinggal di pedesaan memperlihatkan insidensi penyakit parkinson yang meningkat (Abbas et al., 2018).

\section{Hubungan Hilangnya Fungsi Penghidu (Anosmia) dengan Penyakit Parkinson}

Hilangnya fungsi penghidu (Anosmia) dapat mendahului gejala motorik pada penderita penyakit parkinson baik itu setahun atau hingga satu dekade. Gejala anosmia dapat menjadi gejala pertama dari kelainan patologi pada central nervous system (CNS). Beberapa studi terkait penyakit Parkinson menyatakan hampir semua pasien yang di teliti didapatkan atrofi pada bulbus olfaktori sehingga menyebabkan pasien mengalami kehilangan fungsi penghidu (Anosmia). Didapatkan pula penurunan volume dari bulbus olfaktori (OB) dan pemendekan dari sulkus olfaktori (OS) pada pasien penyakit Parkinson sehingga menyebabkan anosmia pasa pasien (Wang, You and Liu, 2011; Tarakad and Jankovic, 2017).

Patologi lainnya yang dipercaya menjadi penyebab anosmia pada penyakit Parkinson adalah terdapat kelainan pada pusat penghidu yang ada di otak sehingga menyebabkan berkurangnya fungsi persepsi bau. Temuan ini dibuktikan dari hasil MRI pasien memperlihatkan gambaran peningkatan difusifitas pada regio dari bulbus olfaktori dibandingkan dengan pasien tanpa penyakit Parkinson (Scherfler et al., 2006; Fujio et al., 2019).

Pengaruh neurotransmitter juga diduga menjadi penyebab gejala anosmia dapat muncul. Beberapa neurotransmiter yang berperan dalam progresivitas penyakit parkinson telah menunjukkan hubungan dengan hilangnya penciuman, termasuk dopamin, asetilkolin, dan serotonin (Wang, You and Liu, 2011; Höglinger et al., 2015). Dopamin telah lama diketahui memainkan peran utama dalam patogenesis PD, tetapi baru-baru ini hubungannya dengan hilangnya penciuman telah dieksplorasi (Höglinger et al., 2015). Penelitian telah menunjukkan korelasi antara tes penciuman dan aktivitas transporter dopamin (DAT) di substansia nigra, striatum, dan hippocampus pada pasien penyakit parkinson. Hasil penelitian tersebut menunjukkan bahwa terdapat hubungan antara aktivitas dari dopamine terhadap fungsi penghidu, begitupula dengan asetilkolin (Doty, 2012; Fullard, Morley and Duda, 2017).

Neurotransmiter ketiga yang kemungkinan berhubungan dalam patogenesis disfungsi penciuman pada penyakit parkinson adalah serotonin. Serotonin muncul dari inti raphe, yang mengirimkan proyeksi ke bulbus olfaktorius (Petzold, Hagiwara and Murthy, 2009). Pada pasien dengan penyakit Parkinson, patologi Lewy (badan lewy) ditemukan di inti raphe bersama dengan penipisan serotonin yang nyata di bulbus olfaktorius dan area lain dari sistem penciuman sehingga menyebabkan menurunnya hingga hilangnya fungsi penghidu (Doty, 2012; Fullard, Morley and Duda, 2017). 


\section{Test Penghidu untuk Mendeteksi Anosmia}

Menilai adanya anosmia dapat dilakukan dengan beberapa cara (Barresi et al., 2012). Gangguan penciuman pada penyakit parkinson dapat dilihat dengan ambang penciuman yang lebih tinggi atau olfactory threshold test (yang dapat didefinisikan sebagai konsentrasi terendah dari molekul bau yang dapat dirasakan oleh individu), berkurangnya identifikasi dan diskriminasi penciuman (yang dapat didefinisikan sebagai penurunan kemampuan untuk benar mengidentifikasi bau yang berbeda, dan membedakannya), dan gangguan memori penciuman (yang dapat didefinisikan sebagai gangguan ingatan bau) (Haehner, Hummel and Reichmann, 2011; Tarakad and Jankovic, 2017).

Konsep yang digunakan dalam tes ambang batas (olfactory threshold test) adalah bahwa subjek berulang kali dipaparkan pada bau yang sama dengan konsentrasi naik dan turun lalu diharuskan untuk mengidentifikasi konsentrasi yang paling tidak terdeteksi atau bau dengan konsentrasi paling rendah untuk bau individu ini (Haehner, Hummel and Reichmann, 2011). Langkah-langkah lain untuk menilai kehilangan penciuman mungkin termasuk penyelidikan kualitas hidup pasien, misalnya, dengan menggunakan kuesioner "Questionnaire for Olfactory Dysfunction", atau riwayat pasien terkait potensi peristiwa yang menggangu penciuman (Mattos et al., 2019).

Tes lain yang umum digunakan adalah tes identifikasi bau (Haehner, Hummel and Reichmann, 2011). Dalam tes identifikasi bau, bau disajikan pada konsentrasi ambang batas dan subjek diminta untuk mengidentifikasi bau dari daftar deskriptor. Prosedur pilihan paksa ini mengontrol bias respons subjek (Haehner, Hummel and Reichmann, 2011; Altinayar et al., 2014). Masalah utama yang didapati pada tes identifikasi bau adalah sangat bergantung pada kemampuan verbal subjek. Selain itu, uji identifikasi bau memiliki prasyarat budaya yang kuat karena tidak semua bau dikenal sama baiknya di berbagai kelompok budaya dan kelompok masyarakat (Haehner, Hummel and Reichmann, 2011).

\section{Tatalaksana Gangguan Penghidu pada Penderita Penyakit Parkinson}

Tidak seperti kebanyakan gejala motorik dan nonmotorik yang dialami oleh penderita penyakit Parkinson seperti kelemahan otot, bradykinesia dan kekakuan otot, anosmia tidak berespons terhadap levodopa atau obat simtomatik untuk penyakit Parkinson lainnya (Tarakad and Jankovic, 2017). Treatment yang digunakan pada penderita gangguan penghidu pada penyakit ini adalah Olfactory training atau pelatihan penciuman yang dapat menghasilkan perbaikan pada fungsi indra penciuman (Tarakad and Jankovic, 2017). Dalam satu studi cross-sectional dengan 224 pasien PD, pasien PD awal yang menggunakan rasagiline ditemukan memiliki diskriminasi bau yang lebih baik daripada mereka yang tidak, meskipun perbedaan ini tidak ada pada pasien dengan durasi penyakit yang lebih lama (>8 tahun) (Haehner et al., 2015).

Untuk prosedur pelatihan penciuman standar, pasien mengendus dua kali sehari (sebaiknya sekali di pagi hari sebelum sarapan dan sekali di malam hari sebelum tidur) selama setidaknya 20 hingga 30 detik pada masing-masing dari empat aroma secara terpisah. Itu berarti pasien tidak hanya sesekali mengendus bau. Pasien yang melakukan 
pelatihan penciuman harus fokus mengendus bau yang berbeda secara intensif dan mengikuti protokol yang erat ini (Kronenbuerger and Pilgramm, 2020).

Bau untuk pelatihan disajikan dalam botol atau stoples hirupan. Biasanya, pasien melakukan pelatihan penciuman setidaknya selama 24 minggu. Pada pasien dengan disfungsi penciuman pasca-infeksi, pelatihan penciuman selama satu tahun menghasilkan hasil yang lebih baik daripadapelatihan selama 16 minggu (Konstantinidis, Tsakiropoulou and Constantinidis, 2016). Studi lain menunjukkan bahwa pelatihan penciuman dengan 12 bau lebih efektif daripada pelatihan dengan 4 bau pada pasien dengan disfungsi penciuman pasca-infeksi (Altundag et al., 2015). Sebuah studi ketiga menunjukkan bahwa konsentrasi tinggi bau lebih efektif daripada konsentrasi rendah bau untuk pelatihan penciuman pada pasien dengan disfungsi penciuman pasca-infeksi. Namun, pengamatan ini belum dipelajari pada pasien dengan disfungsi penciuman karena etiologi lain. Untuk pasien ini, pelatihan penciuman mengikuti protokol standar (yaitu, pelatihan penciuman dengan empat bau berbeda dalam konsentrasi standar dua kali sehari selama setidaknya 24 minggu) mungkin merupakan titik awal yang baik (Kronenbuerger and Pilgramm, 2020).

Hasil meta analisis terkait tatalaksana pelatihan penciuman didapatkan Sebanyak sepuluh studi dengan 639 pasien diidentifikasi dan ditinjau secara sistematis. Data yang cukup untuk meta-analisis tersedia untuk 3 studi (Pekala et al., 2017; Saatci et al., 2020). Pasien yang menerima tatalaksana pelatihan penciuman mengalami peningkatan yang signifikan secara statistik dalam skor TDI (Ambang Batas, Diskriminasi, Identifikasi) dibandingkan dengan pasien control ( $\mathrm{p}$ value=3.77). Peningkatan fungsi penciuman diamati pada diskriminasi ( $\mathrm{p}$ value $=1.92$ ) dan identifikasi ( $\mathrm{p}$ value $=1,61$ ), tetapi tidak pada ambang penciuman (p value <0,01)(Pekala et al., 2017). Jadi, pelatihan penciuman adalah modalitas yang menjanjikan untuk pengobatan disfungsi penciuman. Hasil tinjauan sistematis dan meta-analisis ini menunjukkan bahwa ini mungkin pengobatan yang efektif untuk disfungsi penciuman karena berbagai etiologi. Studi tambahan berkualitas tinggi diperlukan untuk menentukan indikasi, hasil, dan durasi terapi untuk terapi baru ini (Pekala et al., 2017).

\section{Kesimpulan}

Anosmia merupakan gejala non-motorik yang paling sering dijumpai pada penyakit Parkinson, dan sering mendahului gejala motorik pada penyakit Parkinson. Penelitian menyatakan adanya atrofi pada bulbus olfaktori sertaperan dari berbagai neurotransmitter dipercaya mengakibatkan anosmia pada penderita penyakit Parkinson. Pelatihan penciuman adalah modalitas yang menjanjikan untuk pengobatan disfungsi penciuman dan anosmia. Hasil tinjauan sistematis dan meta-analisis ini menunjukkan bahwa ini mungkin pengobatan yang efektif untuk disfungsi penciuman karena berbagai etiologi. Studi tambahan diperlukan untuk menentukan indikasi, hasil, dan durasi terapi untuk terapi baru ini. 


\section{BIBLIOGRAFI}

Abbas, M. M. et al. (2018) 'Epidemiology of Parkinson 's Disease — East Versus West', 5(December 2017), pp. 14-28. doi: 10.1002/mdc3.12568. Google Scholar

Altinayar, S. et al. (2014) 'Olfactory disfunction and its relation olfactor bulbus volume in Parkinson' s disease', i, pp. 3659-3664. Google Scholar

Altundag, A. et al. (2015) 'Modified Olfactory Training in Patients With Postinfectious Olfactory Loss', (August), pp. 1763-1766. Google Scholar

DeMaagd, G. and Philip, A. (2015) 'Parkinson's Disease and Its Management', 40(8), pp. 504-511. Google Scholar

Doty, R. L. (2012) 'Olfactory dysfunction in Parkinson disease', Nature Publishing Group. Nature Publishing Group, 8(6), pp. 329-339. doi: 10.1038/nrneurol.2012.80. Google Scholar

Emamzadeh, F. N. and Surguchov, A. (2018) 'Parkinson' s Disease : Biomarkers , Treatment , and Risk Factors', 12(August), pp. 1-14. doi: 10.3389/fnins.2018.00612. Google Scholar

Fujio, H. et al. (2019) 'Characteristics of Smell Identification Test in Patients With Parkinson Disease', 12(2), pp. 206-211. Google Scholar

Fullard, M. E., Morley, J. F. and Duda, J. E. (2017) 'Olfactory Dysfunction as an Early Biomarker in Parkinson' s Disease', Neuroscience Bulletin. Springer Singapore, 33(5), pp. 515-525. Google Scholar

Haehner, A. et al. (2015) 'Early Parkinson's disease patients on rasagiline present with better odor discrimination', Journal of Neural Transmission. Springer Vienna. doi: 10.1007/s00702-015-1433-1. Google Scholar

Haehner, A., Hummel, T. and Reichmann, H. (2011) 'Olfactory Loss in Parkinson' s Disease', 2011(Figure 2). Google Scholar

Höglinger, G. U. et al. (2015) 'A new dopaminergic nigro - olfactory projection', Acta Neuropathologica. Springer Berlin Heidelberg. Google Scholar

Konstantinidis, I., Tsakiropoulou, E. and Constantinidis, J. (2016) 'Long term effects of olfactory training in patients with post-infectious olfactory loss *', (8), pp. 170175. doi: 10.4193/Rhino15.264. Google Scholar

Kronenbuerger, M. and Pilgramm, M. (2020) Olfactory Training - StatPearls - NCBI Bookshelf, StatPearls. Google Scholar

Mattos, J. L. et al. (2019) 'Factor Analysis of the Questionnaire of Olfactory Disorders in Patients with Chronic Rhinosinusitis', Int Forum Allergy Rhinol, 8(7), pp. 777782. doi: 10.1002/alr.22112.Factor. Google Scholar

Pekala, K. et al. (2017) Efficacy of olfactory training in patients with olfactory loss: a systematic review and meta-analysis. Dallas.. Google Scholar

Petzold, G. C., Hagiwara, A. and Murthy, V. N. (2009) 'Serotonergic modulation of odor input to the mammalian olfactory bulb', 12(6).. Google Scholar

Rashed, K. H. et al. (2020) 'Patterns of olfactory dysfunctions in patients with Parkinson 
disease'. The Egyptian Journal of Neurology, Psychiatry and Neurosurgery, pp. 06. Google Scholar

Saatci, O. et al. (2020) 'Olfactory training ball improves adherence and olfactory outcomes in post - infectious olfactory dysfunction', European Archives of OtoRhino-Laryngology. Springer Berlin Heidelberg, (0123456789). Google Scholar

Scherfler, C. et al. (2006) 'Voxel-wise analysis of diffusion weighted imaging reveals disruption of the olfactory tract in Parkinson' s disease', pp. 538-542. Google Scholar

Storstein, O. T. A. (2017) 'Epidemiology of Parkinson 's disease Diagnosis of PD', Journal of Neural Transmission. Springer Vienna, (1).. Google Scholar

Tarakad, A. and Jankovic, J. (2017) Anosmia and Ageusia in Parkinson 's Disease. 1st edn, Nonmotor Parkinson's: The Hidden Face. 1st edn. Elsevier Inc.. Google Scholar

Wang, J., You, H. and Liu, J. (2011) 'Association of Olfactory Bulb Volume and Olfactory Sulcus Depth with Olfactory Function in Patients with Parkinson Disease'. Google Scholar

First publication right:

Jurnal Syntax Fusion: Jurnal Nasional Indonesia

This article is licensed under:

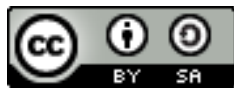

